\title{
Jenis Keluhan dan Cara Penanganan Keluhan di Hotel Holiday Inn Resort Baruna Bali
}

\author{
Gede Rendrawan, Trianasari, A.A. Ngr. Yudha Martin Mahardika \\ Undiksha
}

\begin{abstract}
Abstrak
Penelitian ini bertujuan untuk mengetahui jenis pengaduan dan cara penanganan departemen $f$ \& b service pada Hotel Baruna Bali Holiday Resort. Penelitian ini merupakan penelitian deskriptif kualitatif dengan menggunakan wawancara dan observasi sebagai metode pengumpulan datanya. Informan yang berpartisipasi dalam penelitian ini adalah tour operator bidang administrasi. Hasil penelitian menunjukkan bahwa terdapat beberapa jenis keluhan pada Departemen F\&B Service Hotel Baruna Bali Holiday Resort. Hasil penelitian menunjukkan bahwa jenis keluhan yang disampaikan oleh F\&B Service Department di Baruna Bali Holiday Resort Hotel adalah kurangnya pelayan / pramusaji yang profesional, saat melayani tamu, pelayan / pramusaji kurang sopan saat melayani tamu, tamu menunggu pesanan terlalu lama. Terdapat prosedur penanganan keluhan tamu di F\&B Service Department di Baruna Bali Holiday Resort Hotel bernama ILEAD. Prosedur ini berfungsi sebagai pedoman bagi karyawan di departemen f\&B service dalam menangani pengaduan.
\end{abstract}

Kata kunci: f\&B departemen, jenis pengaduan, penanganan pengaduan

\begin{abstract}
This study aims to determine the types of complaints and how to handle the department $f \& b$ service at the Hotel Baruna Bali Holiday Resort. This research is a qualitative descriptive study using interviews and observations as a method of collecting data. The informants who participated in this study were tour operators in the field of administration. The results showed that there were several types of complaints at the F\&B Service Department at the Baruna Bali Holiday Resort Hotel. The results showed that the types of complaints by the F\&B Service Department at Baruna Bali Holiday Resort Hotel were the lack of professional waiters / waitresses, when serving guests, waiters / waitresses were not polite when serving guests, guests waiting for orders too long. There is a procedure for handling guest complaints at the F\&B Service Department at the Baruna Bali Holiday Resort Hotel called ILEAD. This procedure serves as a guideline for employees in the department $f \& b$ service in handling complaints.
\end{abstract}

Keywords: department $f$ \& b service, complaints type, complaints handling

\section{Pendahuluan}

Industri jasa atau layanan memiliki karakteristik yang berbeda dengan industri produk manufaktur. Salah satu ciri khas sebuah layanan adalah interaksi antara pemberi dan penerima layanan. Pada dasarnya hotel merupakan properti yang sangat mengutamakan pelayanan yang profesional di samping fasilitas yang tersedia di hotel tersebut. Tamu hotel membutuhkan kualitas fasilitas dan pelayanan yang sesuai dengan apa yang diharapkan tamu. Oleh karena itu, demi menciptakan kualitas yang diinginkan oleh tamu, hotel akan melakukan pembaruan dalam waktu tertentu terhadap standar pelayanan dan fasilitas yang ada. Di kota-kota besar, terdapat hotel berbintang yang berdiri dan saling bersaing di dunia 
JMPP, Vol 3 No 1, April 2020

p-ISSN: 2654-9719

industri perhotelan. Aspek hotel yang berbintang sejatinya sangat mengedepankan pelayanan dan fasilitas yang dimiliki.

Menurut Rumekso (2001), hotel merupakan sebuah bangunan yang menyediakan fasilitas untuk tamu seperti kamar untuk mereka menginap atau beristirahat, restoran untuk tempat makan dan minum, serta fasilitas penunjang lainnya. Sedangkan menurut I Gusti Bagus (2016) hotel merupakan suatu bangunan yang menyediakan akomodasi baik dalam pelayanan penginapan, penyediaan fasilitas penunjang maupun penyediaan pelayanan makanan dan minuman yang dikelola secara profesional. Pelayanan yang diberikan kepada tamu yang menginap di hotel harus maksimal dan profesional agar tamu merasa sangat senang saat berada di hotel. Pelayanan yang tidak maksimal membuat tamu merasa tidak puas saat berada di hotel atau saat menginap di hotel sehinggaakantimbul keluhan daritamu. Dari segi pelayanan, tergantung bagaimana cara staf melayani atau menanggapi tamu yang datang. Belum tentu staf yang memiliki pendidikan yang cukup tinggi memiliki pelayanan yang baik, staf yang hanya berbekal ijazah seadanya terkadang lebih baik dalam pelayanan. Pada saat memberikan pelayanan atau etika yang benar sangat di butuhkan kesabaran yang tinggi apalagi jika sedang menangani keluhan para tamu. Pada kondisi seperti itu kita harus tenang dalam menanganinya, memberikan ucapan yang sopan agar tamu tidak tersinggung, dan juga agar terciptanya hubungan yang baik antara karyawan hotel dengan tamu hotel. Selain itu dalam menangani keluhan atau memberikan pelayanan harus memiliki pengetahuan yang cukup, penampilan yang menarik, attitude/sikap yang menentukan keberhasilan kerja. Staf yang bekerja atau melayani harus paham betul tentang bagaimana beretika yang baik dan sopan, staf juga harus mampu menangani keluhan tamu dengan baik dengan menggunakan etika attitude yang baik dalam menangani keluhan. Jika pelayanan yang diterima tamu baik, maka akan memberikan kesan positif kepada tamu, sehingga kesejahteraan para pegawainya ikut membaik di kemudian hari.

Staff hotel sebaiknya dibiasakan dapat menangani keluhan dengan tenang dan tidak tergesa-gesa. Dalam menangani keluhan dengan sopan dan tenang sesuai. Menurut Moenir dalam Yudha (2011:17), pelayanan merupakan suatu kegiatan yang di lakukan oleh seseorang atau bahkan sekelompok orang dalam hal untuk memenuhi permintaan sesuai dengan hak konsumem. Oleh karena itu karyawan dan staf hotel yang harusterlatih dan dapat berkompetisi lebih baik. Pelayanan sendiri juga berhubungan dengan sopan santun dan kebiasaan dalam menjalankan tugas melayani tamu. Tamu merupakan prioritas hotel yang harus dipenuhi keinginannya. pihak hotel harus bisa menangani segala bentuk keluhan yang diberikan oleh tamu. Selain itu, pihak hotel juga harus dapat memenuhi kebutuhan tamu. Dalam beberpa kasus, tamu memberikan keluhan bukan karena fasilitas yang kurang baik, tetapi karena pelayanan yang kurang dalam pemenuhan kebutuhan tamu. Oleh sebab itu, etika yang baik perlu diutamakan dalam pelayanan tamu dan harus sesuai dengan standar hotel. Beberapa 
JMPP, Vol 3 No 1, April 2020

p-ISSN: 2654-9719

hotel, standar yang diberikan berasal dari bagaimana ulasan dari tamu yang menginap, dan hotel tersebut menyesuaikan bagaimana cara memenuhi kebutuhan tamu yang menginap di hotel tersebut. Selain beberapa hal di atas adapun cara lain yang perlu kita ketahui atau kita lakukan pada saat menangani keluhan tamu. Antara lain, mendengarkan ujaran tamu sampai tamu benar-benar tuntas menjelaskan apa yang menjadi penyebab ketidakpuasan tersebut. Jangan pernah menyela atau memotong pembicaraan tamu yang sedang komplain agar tidak menimbulkan masalah baru. Disini tamu biasanya akan memberikan saran atau pendapatnya mengenai masalah tersebut. Karyawan atau staf harus menerapkan etika yang sesuai dengan prinsip perusahaan. Penerapan etika biasanya banyak dilakukan oleh perusahaan yang bergerak dibidang jasa seperti hotel karena prusahaan dibidang jasa lebih banyak berhubungan langsung dengan konsumen. Hal tersebut memungkinkan penerapan etika yang baik dan sesuai dengan standar dari perusahaan tersebut, selain beberapa hal yang sudah dijelaskan sebelumnya etika juga dipengaruhi dari standar pendidikan dan pengalaman seseorang dalam menangani konsumen. Rasa percaya diri dan juga gerak gerik dalam melayani konsumen juga merupakan salah satu faktor pendukung. Keluhan yang dapat teratasi dengan baik sesuai dengan etika dan perilaku yang baik, dapat memberikan dampak positif bagi pihak hotel.

Dalam kegiatan operasional hotel, pemberi jasa pelayanan adalah karyawan yang langsung berinteraksi dengan tamu dengan memberikan sebuah pelayanan yang dapat membuat tamu merasa senang ketika berada di hotel.Saat interaksi ini adalah saat yang krusial, karena pelanggan benar-benar merasakan layanan. Jadi, terlepas dari iklan atau citra atau janji sebuah bisnis jasa kepada calon pelanggannya, momen saat mana jasa itu disampaikan adalah momen pembuktian kualitas layanan. Tidak mengherankan jika momen ini dikenal dengan istilah 'the moment of truth'. Moments of truth adalah pengalaman paling berkesan yang didapatkan saat berinterkasi dengan pelayanan. Menurut Sutanto (2009) the moment of truth adalah pengalaman yang dirasakan oleh tamu ketika tamu menerima jasa pelayanan dan tamu merasakan hal yang membuat tamu merasa senang dalam pelayanan yang dinerikan. Pelayanan secara profesional yang diberikan kepada tamu memiliki kesan yang positif, titik sentuhan yang membuat tamu merasakan senang menikmati fasilitas hotel.

Dalam kegiatan operasional hotel, the moment of truth dapat dilihat dari adanya interaksi antara karyawan hotel dengan tamu yang menikmati pelayanan hotel. Pemberian pelayanan yang baik kepada tamu akan menciptakan kepuasan tamu. Apabila tamu merasa puas dengan pelayanan hotel, mereka akan melakukan kunjungan yang berulang-ulang (repeater) dan merekomendasikan kepada orang orang lain, kerabatan maupun saudara untuk melakukan kunjungan di tempat yang sama. Semakin banyaknya wisatawan yang berkunjung ke suatu obyek wisata atau semakin berkembangnya suatu daerah karena pariwisatanya maka perlu dibutuhkan kualitas pelayanan hotel yang berkualitas dan terbaik. 
Dalam kaitannya dengan pelayanan hotel, restoran menjadi salah satu akomodasi hotel yang mengutamakan kepuasan tamu. Fera (2009), menyatakan bahwa restoran merupakan suatu pelayanan jasa pangan yang menyediakan pelayanan makanan dan minuman dimana di dalam restoran terdapat pamusaji yang melayani, menerima, dan memberikan suatu pelayanan penuh kepada tamu. Dalam halnya memberikan suatu pelayanan kepada tamu, pramusaji diharapkan selalu bersikap baik, jujur, ramah, senyum dalam melayanani tamu dan bertanggungjawab atas pekerjaan melayani tamu khusus nya pada Department F\&B Service.

Dalam sebuah pelayanan di hotel pada khususnya dibidang makanan dan minuman, pramusaji menjadi barisan terdepan dalam hal pelayanan. Menurut Fitrianda (2017:49), pramusaji merupakan karyawan hotel yang mempunyai tugas dan tanggungjawab atas pelayanan makanan dan minuman yang diberikan secara profesional. Sedangkan menurut Earlike (2016), pramusaji merupakan jabatan yang terdapat di bagian penjualan makanan dan minuman pada F\&B Department seperti bagian restoran, bar, banquet dan room service. Pelayanan pada Department F\&B Service ini memiliki tujuan dalam menciptakan suatu pengalaman yang diberikan kepada tamu antara lain tamu akan selalu merasa puas dan akan selalu ingin merasakan lagi sevice yang pernah diberikan.

Selain beberapa hal di atas adapun pentingnya penanganan keluhan tamu demi menjaga kualitas dan kuantitas dari jasa maupun produk itu sendiri. Selain itu nantinya di kemudian hari para staf yang melakukan peyalan kepada tamu agar lebih aware dan lebih tanggap dalam menghadapi keluhan atau saran dari tamu, jangan sampai membuat komplain, sekecil apapun komplain akan berakibat fatal bagi pihak hotel maupun dari pihak tamu itu sendiri. Kepuasan tamu hotel menjadi kunci keberhasilan kegiatan hotel. Kepuasan tamu terhadap layanan yang diberikan sangat tergantung pada sumber daya manusia yang dapat menjalankan tugasnya dengan baik sesuai dengan standar perusahaan, oleh sebab itu penting menunjukkan prinsip bahwa penempatan sumber daya manusia harus tepat dan sesuai dengan kemampuannya. Oleh karena itu perusahaan harus memegang jaminan terhadap mutu layanan sangat hati-hati dalam menyeleksi dan menempatkan karyawan yamg sesuai dengan bidang tugas pekerjaannya karena apabila tidak resiko yang sangat besar bisa saja terjadi dan bisa menyebabkan kerugian bagi perusahaan atau hotel.

\section{Tinjauan Pustaka}

\section{Definisi Department F\&B Service}

Pada umumnya Department F\&B Service merupakan departemen yang bergerak dalam bidang jasa pelayanan makanan dan minuman. Jasa pelayanan yang diberikan secara profesional kepada tamu memberikan kesan yang baik kepada tamu sehingga tamu akan selalu ingat dan merasa ingin di layani kembali. Menurut Kurisnawan (2017), F\&B Service merupakan suatu aktivitas pelayanan produksi yang meliputi pelayanan makanan dan 
JMPP, Vol 3 No 1, April 2020

p-ISSN: 2654-9719

minuman kepada tamu secara profesional sehingga akan timbul hal positif bagi citra perusahaan.

\section{Jenis Keluhan Tamu}

Menurut Norwel (2005:27) dalam Sitanggang (2017), menyatakan bahwa terdapat 4 jenis komplin diantaranya mechanical complaints, atitudinal complaints, service related complaint, unusual complaints. Mechanical Complaints yaitu jenis komplin yang di sebabkan oleh perlengkapan hotel, misalnya kamar tidak bersih, aroma kamar tidak sedap, AC (air conditioner) tidak berfungsi dengan baik dan lain sebagainya. Atitudinal complaints merupakan jenis keluhan yang sebabkan oleh pelayanan dan tingkah laku karyawan yang kurang baik, misalnya tidak senyum pada saat melayani, tidak sopan kepada tamu, dan lain sebagainya. Service related complaints merupakan jenis keluhan tamu yang terjadi akibat kurang profesional karyawan dalam melayani tamu, misalnya salah menghantarkan pesanan tamu, terlalu lama menunggu makanan dan minuman yang di pesan dan lain sebagainya. Unusual complaints merupakan jenis komplain yang terjadi akibat tidak disediakannya ruang khusus bagi para perokok maupun tidak perokok.

\section{Penanganan Keluhan Tamu}

Penanganan keluhan merupakan hal yang perlu diperhatikan oleh setiap hotel. Penanganan keluhan yang efektif memberikan peluang untuk membuat pola pikir tamu menjadi hal positif yang semula tidak puas menjadi puas terhadap pelayanan dan fasilitas yang di nikmati agar tamu tidak mudah merasa kecewa sehingga pihak hotel tidak kehilangan pelanggan dan bahkan bisa menjadi pelanggan yang abadi. Standar yang tepat untuk melayani keluhan tamu adalah mendekati tamu dan dengarkan keluhan yang disampaikan dengan hati terbuka. Tawarkan bantuan kepada tamu dan dengarkan dengan baik jika tamu mengutarakan keluhan yang di alaminya. Gunakan kebijaksanaan untuk mengatasi keluhan dari tamu dan jika tidak terselesaikan atau di luar kemampuan bisa di serahkan kepada supervisor atau senior yang terbiasa menangani keluhan tamu dan manajer. Amrullah (2017) menyatakan bahwa ada 6 cara penanganan keluhan dari tamu sebagai berikut:

1. Dekati tamu tanyakan ada bisa di bantu.

2. Dengarkan saat tamu mengutarakan keluhannya dengan baik sampai tamu selesai mengutarakan keluhan.

3. Sebelum menjawab keluhan dari tamu karwayan yang menangani keluhan selalu berkata maaf sebelum memulai percakapan.

4. Catat jenis keluhannya dalam log book atau buku khusus yang mencatat segala keluhan dari tamu dan pelajari masalahnya. 
JMPP, Vol 3 No 1, April 2020

p-ISSN: 2654-9719

5. Setelah di periksa coba atasi masalahnya dan jelaskan kepada tamu tindakan apa yang akan diambil agar tamu tidak merasa kecewa

6. Jika masalahnya tidak menemukan titik temu, mintalah direct supervisor untuk penanganan lebih lanjut.

Setiap hotel yang berorientasi pada pelanggan perlu menyediakan akses yang mudah dan nyaman bagi para tamu untuk menyampaikan saran, kritik, penadapat dan keluhan yang mereka alami, penanganan keluhan tamu memberikan peluang untuk mengubah layanan dan fasilitas menjadi lebih baik. Ada empat aspek dalam menangani keluhan tamu yaitu empati, kecepatan penanganan komplain, keawajaran dalam memecahkan masalah, kemudahan tamu untuk menyampaikan keluhan. Empati, dalam menghadapi tamu komplain yang marah atau emosi karyawan perlu bersikap empati yang artinya karyawan dapat memahami situasi yang dirasakan tamu. Dengan demikian permasalahan yang dihadapi dapat diselesaikan. Kecepatan dalam menangani komplain merupakan hal yang sangat penting dalam penanganan keluhan tamu adar tamu tidak lama-lama meredam keluhannya yang berakibat pada hilangnya pelanggan hotel. Keluhan yang diatasi dengan cepat dapat mengurangi rasa kecewa yang dirasakan oleh tamu dan tidak kehilangan pelanggan. Kewajaran, kewajaran disini bisa di artikan keadilan dalam memecahkan masalah atau bisa di artikan sebagai kompensasi terhadap tamu yang komplain. kemudahan tamu untuk melakukan keluhan. Hal ini sangat penting bagi tamu utnuk menyampaikan keluhannya.

\section{Metode Penelitian}

Jenis penelitian yang dilakukan adalah penelitian kualitatif. Menurut Sugiyono (2008:2), penelitian kualitatif adalah suatu metode penelitian yang digunakan untuk meneliti suatu kondisi apa, mengapa, dan bagaimana fenomena itu bisa terjadi. Penelitian kualiitatif bertujuan untuk memahami fenomena yang terjadi dilapangan, jenis-jenis keluhan yang terjadi, perilaku karyawan saat menghadapi keluhan, dan bagaimana karyawan mengatasi keluhan dengan efektif. Jenis penelitian ini termasuk jenis penelitian deskriptif. Menurut Linarwati (2016), penelitian deskriptif merupakan penelitian yang bertujuan untuk mendeskripsikan suatu keadaan objek atau subjek penelitian secara alamiah maupun fenomena buatan manusia. Fenomena itu bisa berupa bentuk, aktivitas, karakteristik, perubahan, hubungan, kesamaan, dan perbedaan antara fenomena yang satu dengan fenomena lainnya. Penelitian deskriptif merupakan penelitian yang sangat sederhana dibandingkan dengan penelitian lainnya, peneliti tidak melakukan penambahan, mengubah, dan memanipulasi objek yang diteliti. Penelitian ini bertujuan untuk menjelaskan informasi dasar mengenai fenomena yang sedang diteliti.

Penelitian ini dimulai dengan observasi pada subjek penelitian yaitu Manager Envy Restaurant pada Department F\&B Service dan Supervisor Poolbar. Rumusan masalah Jurnal Manajemen Perhiotelan dan Pariwisata| 15 
JMPP, Vol 3 No 1, April 2020

p-ISSN: 2654-9719

nantinya akan dijawab dengan cara pengumpulan data dengan metode wawancara online dan metode dokumentasi. Setelah data dikumpulkan dengan lengkap, data akan diolah dengan teknik deskriptif kualitatif guna memaparkan serta memberikanpenjelasan mengenai data-data yang didapat pada saat wawancara online dan nantinya akan ditarik kesimpulan sesuai dengan hasil penelitian.

\section{Hasil Penelitian dan Pembahasan}

Jenis-jenis Keluhan Pada Department F\&B Service Di Hotel Holiday Inn Resort Baruna Bali

Berdasarkan pemaparan narasumber pada penelitian ini, terdapat beberapa Jenis-jenis keluhan pada Department F\&B Service Di Hotel Holiday Inn Resort Baruna Bali. Pada Department Envy Restaurant, beliau menjelaskan tentang jenis-jenis keluhan di antaranya yaitu pada saat tamu memesan makanan, tamu sering menunggu terlalu lama misalnya pada saat memesan makanan seperti pizza, tamu sering melakukan komplin dengan menyatakan sudah sangat lama menunggu pesanannya. Kemudian jenis keluhan lainnya yaitu tamu tidak mendapatkan informasi yang lengkap dikarenakan karyawan tidak menjelaskan dengan lengkap. Salah satu contohnya yaitu pada saat tamu selesai dinner, ketika tamu memesan satu maincourse itu akan mendapatkan kids eat free tetapi tamu tidak mengetahui informasi tersebut. Jenis komplin lainnya yaitu kurang profesional nya pramusaji dalam membawakan makanan dan minuman. Pada saat tamu menikmati makanan dan minuman nya, tamu menemukan seperti staples pada makanan mereka. Hal ini terlihat jelas pramusaji tidak profesional terutama mengecek makanan tamu sebelum dihidangkan. Jenis keluhan selanjutnya yaitu pramusaji tidak bersikap baik kepada tamu. Pada saat tamu hendak memesan makanan pramusaji memberikan pertanyaan kurang berkenan di hati tamu, pramusaji menanyakan punya uang atau tidak, hal ini jelas tidak sopan menanyakan hal seperti itu kepada tamu. Pada Department Pool Bar, beliau memaparkan adanya sedikit keluhan yang terjadi pada department pool bar. Keluhannya yaitu tidak disediakannya menu Indian Food. Keluhan selanjutnya yaitu ketika sedang high season situasi di poolbar sangat ramai, pesanan yang membeludak dapat menyebabkan salah dalam menghartakan minuman yang dipesan tamu. Jenis keluhan lainnya yaitu tamu komplin dikarenakan terlalu lama menunggu pesanan.

Berdasarkan hasil wawancara dengan Bapak I Made Winda selaku Manager Envy Restaurant, dan Bapak I Wayan Karmajaya selaku Supervisor of Pool Bar, dapat disimpulkan bahwa jenis komplin menurut Norwel (2005:27) dalam Sitanggang (2017) sejalan dengan kenyataan di lapangan. Komplin yang terjadi disengaja maupun tanpa disengaja dapat menyebabkan ketidakpuasaan tamu dalam menikmati layanan. Tidak profesional nya Waiter/waitress juga dapat menyebabkan terjadi keluhan.

\section{Penanganan keluhan pada Department F\&B Service}


JMPP, Vol 3 No 1, April 2020

p-ISSN: 2654-9719

Pada industri jasa pelayanan keluhann menjadi salah satu tantangan pada Department $F \& B$ Service, maka dari itu diperlukannya pemecahan masalah untuk mengatasi keluhan yang sering terjadi pada saat memberikan pelayanan tamu. Dengan adanya penangananpenanganan komplin teratasi diharapkan mampu mengurangi dan meminimalisir terjadinya komplin. Komplin yang teratasi akan membuat tamu merasa puas ketika check-out meninggalkan hotel.

Waiter/waitress dalam menjalakan operasional harus memiliki pedoman ILEAD yaitu singkatan dari Identify, Listen, Empathy, Apologize, dan Develop Solution. 1) Identify, artinya ketika Waiter/waitressmelayani tamu yang memiliki complain, hal pertama yang dilakukan yaitu mengidentifikasi apa sebenarnya yang tamu tersebut keluhkan, seperti bertanya apa, kenapa, dan bagaimana keluhan tersebut bisa terjadi. 2) Listen, yaitu mendengarkan secara seksama saat proses mengidentifikasi agar tidak terjadi kesalah pahaman antara tamu dengan Waiter/waitress. 3) Empathy, yaitu memahami perasaan tamu saat itu dengan cara menunjukan rasa empati atau ikut merasakan apa yang tamu rasakan saat itu serta berusaha untuk tetap menjaga suasana yang tenang dan tidak membuat kepanikan. 4) Apologize, yaitu meminta maaf dan permakluman kepada tamu tentang apa yang telah terjadi. Menyampaikan permintaan maaf juga harus dibarengi dengan bahasa tubuh dan nada bicara yang sopan dan bisa diterima dengan baik oleh tamu. 5) Develop Solution, hal ini berkaitan dengan tugasWaiter/waitresssebagai problem solver. Waiter/waitressharus mampu menentukan solusi terbaik terkait keluhan yang terjadi. Solusi yang ditentukan harus berpedoman pada kebijakan hotel, serta solusi itu bisa diterima dengan baik oleh tamu. Solusi bisa dikatakan berhasil apabila tamu merasa puas karena telah dilayani dengan baik dan juga masalah akhirnya dapat teratasi dan tidak menimbulkan kerugian antara tamu dan pihak hotel.

Apabila Waiter/waitress mampu melaksanakan ILEAD tersebut, maka penanganan keluhan telah dilaksanakan yang baik, membuat tamu merasa puas atas pelayanan yang diberikan, serta memberikan citra yang baik terhadap tamu sehingga nantinya nantinya tamu tersebut berpeluang tinggi untuk menggunakan produk dan jasa hotel karena pelayanan yang memuaskan.

Berdasarkan hasil wawancara dengan Bapak I Made Winda selaku Manager Envy Restaurant, dan Bapak I Wayan Karmajaya selaku Supervisor of Pool Bar, dapat disimpulkan bahwa teori penanganan keluhan menurut Amrullah (2017) searah dengan kenyataan di lapangan. Waiter/waitress mampu menyelesaikan suatu keluhan yang terjadi dan memberikan pelayanan yang maksimal guna mengantisipasi komplin dari tamu. 


\section{Penutup}

Berdasarkan pembahasan yang terlah dipaparkan di atas-dapat disimpulkan bahwa mengenai jenis keluhan dan cara penanganan pada department $f \& b$ serivice di Hotel Holiday Inn Resort Baruna Bali adalah sebagai berikut. 1) Adapun beberapa jenis komplin pada Department F\&B Service di antaranya yaitu tamu melakukan keluhan disebabkan oleh karyawan yang tidak profesional salah satu contohnya karyawan tidak teliti melihat makanan tamu apa ada benda yang tidak diinginkan sebelum dihidangkan. Komplin lainnya disebabkan karena tamu terlalu lama menunggu pesanan. 2) Apabila waiter/waitress mampu melaksanakan prosedur ILEAD, maka penanganan keluhan yang terjadi pada department f\&b servicedapat teratasi dengan baik, membangun kembali kepercayaan dari tamu, dan nantinya berpeluang tinggi tamu kembali menggunakan produk dan jasa hotel karena jasa pelayanan hotel yang memuakan. Penanganan keluhan yang teratasi memberikan hal positif dari tamu, tamu merasa sangat diperdulikan ketika melakukan aspirasi mengenai fasilitas hotel.

Penelitian ini belum bisa digeneralisasikan karena masih banyak keterbatasan mengingat lingkup serta jumlah lokasi penelitiannya masih lingkup daerah Bali. Kedepannya diharapkan terdapat peneletian yang membahas topik sama agar mengkaji lebih banyak sumber maupun referensi yang terkait dengan jenis keluhan dan cara penanganan keluhan di Hotel Holiday Inn Resort Baruna Bali

\section{Daftar Pustaka}

Fera, Riska (2009). Pelayanan Pramusaji Dalam Meningkatkan Kenyamanan, Para Tamu Yang Datang Ke Restoran Pandan Sari Hotel Santika Premiere. Yogyakarta (Https://Scholar.Google.Co.Id/Scholar?HI=Id\&As Sdt=0\%2c5\&Q=Pelayanan+Restoran + Di+Hotel\&Btng=\#D=Gs Qabs\&U=\%23p\%3d-3z3czfkuvui)

Fitria Earlike, 2016. Pentingnya Peranan Skill Dan Menu Knowledge Waiter/Waiters Terhadap Kepuasan PelangganFood And Beverage Service Departement. Malang (Https://Scholar.Google.Co.Id/Scholar?HI=Id\&As Sdt=0,5\&Q=Jenis+Keluhan+Di+F\%2 6b+Service\#D=Gs Qabs\&U=\%23p\%3dej99fzruzswi) 22 Juni 2020

I Gusti Bagus, Rai Utama. 2016. Pemasaran Pariwisata. Yogyakarta: Penerbit Cv Andi. (Https://Scholar.Google.Co.Id/Scholar?HI=Id\&As Sdt=0\%2c5\&Q=Penelitian+Terdahul

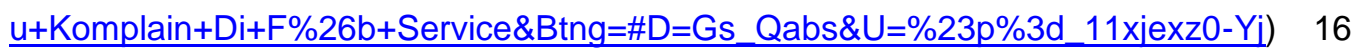
Juni 2020

Linarwati, M. Dkk. (2016). "Studi Deskriptif Pelatihan Dan Pengembangan Sumberdaya Manusia Serta Penggunaan Metode Behavioral Event Interview Dalam Merekrut Karyawan Baru Di Bank Mega Cabang Kudus". Journal Of Management, 2(2), 1-8. (Https://Scholar.Google.Co.Id/Scholar?HI=Id\&As Sdt=0\%2c5\&Q=Linarwati\%2c+M.+Dk 
JMPP, Vol 3 No 1, April 2020

p-ISSN: $2654-9719$

k.+\%282016\%29.+\%22studi+Deskriptif+Pelatihan+Dan+Pengembangan+Sumberdaya

+Manusia+Serta+Penggunaan+Metode+Behavioral+Event+Interview+Dalam+Merekrut

+Karyawan+Baru+Di+Bank+Mega+Cabang+Kudus\%22.+Journal+Of+Management\%2

$\mathrm{c}+2 \% 282 \% 29 \% 2 \mathrm{c}+18 . \& \mathrm{Btng}=\# \mathrm{D}=\mathrm{Gs}$ Qabs\&U=\%23p\%3dofdoxkxe Qaj)

Nuralam, Kurisnawan (2017). Koordinasi Kerja Food And Beverage Service Dengan Food And Beverage Product Dalam Operasional Breakfast Di Hotel Aston Tanjungpinang. Riau (Https://Scholar.Google.Co.Id/Scholar?HI=Id\&As Sdt=0\%2c5\&Q=Food+And+Beverag e++Service+\%28++Soekresno\%2c2006\%29\&Btng=\#D=Gs Qabs\&U=\%23p\%3di6373 h0j1pmi)

Rumekso. 2001. Housekeeping Smk. Bandung: Cv Armico Offset. (Https://Scholar.Google.Co.Id/Scholar?HI=ld\&As Sdt=0\%2c5\&Q=Penelitian+Terdahul u+Komplain+Di+F\%26b+Service\&Btng=\#D=Gs Qabs\&U=\%23p\%3d 11xjexz0-Yj) 16 Juni 2020

Sitanggang, Abnertus Christoper (2017). Pengaruh Penanganan Keluhan Pada Kepuasan Konsumen Di Hotel Grand Praba Bandar Lampung. Lampung (Https://Scholar.Google.Co.Id/Scholar?HI=Id\&As Sdt=0\%2c5\&Q=Norwel+2005\%3a27 +Jenis+Komplain\&Btng=\&Oq=Nor\#D=Gs Qabs\&U=\%23p\%3dyedrs llwtwii)

Sugiyono, 2008. Metode Penelitian Kuantitatif Kualitatif Dan R \& D. Alfabeta, Bandung. (Https://Scholar.Google.Co.Id/Scholar?HI=Id\&As Sdt=0\%2c5\&Q=Sugiyono\%2c+2008. +Metode+Penelitian+Kuantitatif++Kualitatif+Dan+R+\%26+D.+Alfabeta\%2c+Bandung.\& Btng=\#D=Gs Qabs\&U=\%23p\%3dqyv82aejnq0j)

Sutanto, 2009. METODE PENILAIAN KONSUMEN DAN DIMENSI KUALITASJASA BERPENGARUH TERHADAP REVENUE GROWTH. Surabaya.

(https://scholar.google.co.id/scholar?hl=id\&as sdt=0\%2C5\&q=moment+of+truth+pada +operasional+hotel\&btnG=\#d=gs qabs\&u=\%23p\%3DGl 68P0ggccJ) 